University of Nebraska - Lincoln

DigitalCommons@University of Nebraska - Lincoln

November 1990

\title{
Synchrotron radiation induced chemical vapor deposition of thin films from metal hexacarbonyls*
}

\author{
Derrick C. Mancini \\ University of Wisconsin, Madison \\ Shikha Varma \\ Syracuse University \\ John K. Simons \\ University of Wisconsin, Madison \\ Richard A. Rosenberg \\ University of Wisconsin, Stoughton \\ Peter A. Dowben \\ University of Nebraska-Lincoln, pdowben@unl.edu
}

Follow this and additional works at: https://digitalcommons.unl.edu/physicsdowben

Part of the Physics Commons

Mancini, Derrick C.; Varma, Shikha; Simons, John K.; Rosenberg, Richard A.; and Dowben, Peter A., "Synchrotron radiation induced chemical vapor deposition of thin films from metal hexacarbonyls*" (1990). Peter Dowben Publications. 139.

https://digitalcommons.unl.edu/physicsdowben/139

This Article is brought to you for free and open access by the Research Papers in Physics and Astronomy at DigitalCommons@University of Nebraska - Lincoln. It has been accepted for inclusion in Peter Dowben Publications by an authorized administrator of DigitalCommons@University of Nebraska - Lincoln. 


\title{
Synchrotron radiation induced chemical vapor deposition of thin films from metal hexacarbonyls*
}

\author{
Derrick C. Mancini \\ Materials Science Program, University of Wisconsin, Madison, Wisconsin 53706 \\ Shikha Varma ${ }^{\text {a) }}$ \\ Department of Physics, Syracuse University, Syracuse, New York 13244-1130 \\ John K. Simons \\ Department of Chemistry, University of Wisconsin, Madison, Wisconsin 53706 \\ Richard A. Rosenberg \\ Synchrotron Radiation Center, University of Wisconsin, Stoughton, Wisconsin 53589-3097 \\ P.A. Dowben \\ Department of Physics, Syracuse University, Syracuse, New York 13244-1130
}

(Received 29 May 1990; accepted 3 August 1990)

\begin{abstract}
We have studied the initial stages of synchrotron radiation [SR] induced chemical vapor deposition [CVD] of metal-containing thin films from metal hexacarbonyl gases. We have measured the dependence of the initial deposition rate upon gas pressure at room temperature. Substrates were exposed to SR for single fills of the electron storage ring at constant pressure of $\mathrm{Mo}(\mathrm{CO})_{6}, \mathrm{Cr}(\mathrm{CO})_{6}$, or $\mathrm{W}(\mathrm{CO})_{6}$ gas. Deposition was monitored in situ by Auger electron spectroscopy using the SR as the excitation source. The presence of metal, carbon, and oxygen in the deposited films was observed, and the results are consistent with previous studies. Deposition was found to be isolated to areas of the substrate exposed to the SR beam. We discuss these results as they relate to the use of SR as a means to induce CVD and the possibility of patterned deposition using a masked SR source.
\end{abstract}

\section{INTRODUCTION}

The photolytic and electron-beam induced chemical vapor deposition (CVD) of metal films from organometallic sources has been much investigated recently. ${ }^{\prime}$ Of particular interest is the application these methods of deposition to the production of microelectronic devices. ${ }^{2}$ Direct patterned metallization could be an attractive alternative to conventional microlithographic techniques. ${ }^{3-5}$ The metal hexacarbonyls have been extensively studied as source compound for CVD of metal films. ${ }^{1}$ However, when used in laser- or electron-beam induced CVD, the deposited films are often of low quality with significant carbon and oxygen contamination. ${ }^{6-11}$

In the past decade, the feasibility of $x$-ray lithography has been demonstrated for microcircuit production. ${ }^{12}$ With the recent availability of electron storage rings as a source of synchrotron radiation [SR] for $\mathrm{x}$-ray lithography, there is a sufficiently bright source of soft $x$ rays for direct patterned deposition techniques. If the advances in modern $x$-ray optics can be applied to projection lithography techniques using SR, ${ }^{13}$ then SR-induced CVD techniques may become practical for direct lithographic patterning.

Our work is motivated by the anticipation of using metal hexacarbonyls as sources for the SR-induced CVD of metal films with the potential for patterning by $\mathrm{x}$-ray lithography. It is important to determine under what conditions appreciable deposition will occur and the chemical content of the

*Published without author corrections. deposited films. In particular, we investigate the deposition rate at room temperature, the effect of metal hexacarbonyl pressure, and amount of carbon and oxygen contamination in the deposited metal films.

\section{EXPERIMENTAL}

All experiments were performed at the University of Wisconsin Synchrotron Radiation Center [SRC]. SR generated by the Aladdin electron storage ring was used on the SRC "white light" beam line. ${ }^{14} \mathrm{SR}$ is focused by grazing incidence reflection from an Au-coated ellipsoidal mirror at $86.7^{\circ}$ angle of incidence (Fig. 1). This provides a broadband spec-

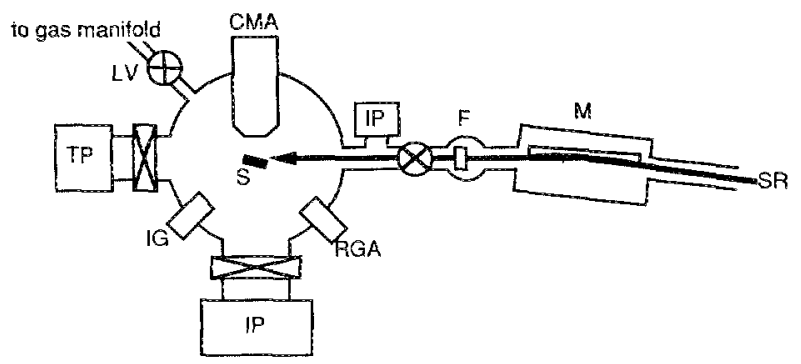

FIG. 1. Schematic of the white light beamline and experimental chamber. Synchrotron radiation (SR) is focused onto the sample (S) by Au mirror (M), and can pass through filter $(F)$. The experimental chamber is separated by a stage of differential pumping (IP). The chamber vacuum is maintained by ion pump (IP) and turbomolecular pump (TP). Auger electrons are analyzed by cylindrical mirror analyzer (CMA). Gas flow is controlled by leak valve (LV) and analyzed by residual gas analyzer (RGA). Substrates are sputtered with ion gun (IG). 
trum of UV and soft X-ray photons at the sample (Fig. 2). A set of filters after the focussing mirror allowed the inclusion of a sapphire optical flat or a $10 \mu \mathrm{m}$ Be thin film in the optical path.

Samples were exposed in a stainless steel ultrahigh vacuum chamber (Fig. 1) with a base pressure less than $10^{-9}$ Torr pumped by a $220 \% / \mathrm{s}$ ion pump and a $170 \% \mathrm{~s}$ turbomolecular pump. The chamber vacuum was isolated from the beamline optics by a single stage of diferential pumping provided by a $20 \ell / \mathrm{s}$ ion pump isolated by two beam apertures. This allowed raising the pressure of the chamber to $10^{-6}$ Torr while maintaining pressure less than $10^{-9}$ Torr in the beamline. Gas was admitted through a variable leak valve to pressures in the range of $10^{-8}-10^{-6}$ Torr as measured by an UHV ionization gauge calibrated for $\mathrm{N}_{2}$. All pressures are reported uncorrected for differences in ionization efficiency of the gases. For metal hexacarbonyis, this likely results in a four- to sevenfold overestimate, due to the greater number of valence electrons per molecule compared to $\mathrm{N}_{2}$.

A gold-coated copper block, $50 \times 12 \times 3 \mathrm{~mm}$, and a Si(111) wafer fragment each were used as substrates. The substrates were mounted on the end of a manipulator at the center of the chamber, allowing accurate and reproducible positioning of the substrate relative to the photon beam and instrumentation in the chamber. The substrate was located siightly past the focus, and the SR was incident at a grazing angle of $10-15^{\circ}$, which resulted in a spot size $\sim 3.0 \times 1.0 \mathrm{~mm}$ and power of $\sim 0.5 \mathrm{~mW}$. This reduced the substrate heating during exposure to less than $10^{\circ} \mathrm{C}$. Deposition was monitored in situ by Auger electron spectroscopy [AES] using the SR as the excitation source. Auger electrons were analyzed by a single-pass cylindrical mirror analyzer [CMA]. The spot size overfilled the acceptance of the CMA, insuring that only the area where deposition occurs is analyzed. This in situ white light SR AES technique allowed the continuous measurement of the Auger spectra as the film is deposited without the contamination often caused by electron gun sources, and has been used previously to monitor organic film deposition. ${ }^{15}$

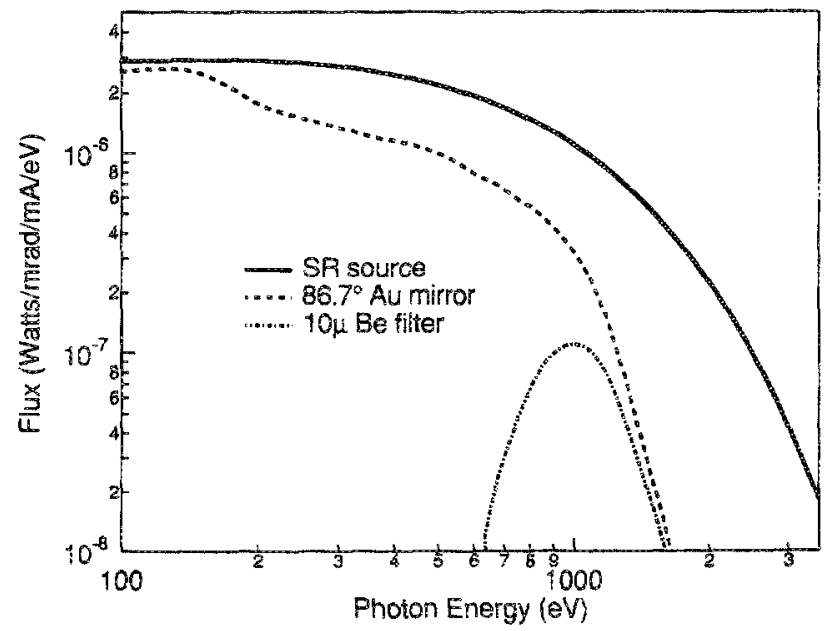

FIG. 2. Power vs photon energy spectrum of $S R$ from the Aladdin electron storage ring at $800 \mathrm{MeV}$, after reffection from the focussing mirror, and after mirror reflection and filtration by $10 \mu \mathrm{Be}$ film.
The substrate was sputtered cleaned by Ar ion bombardment until white light $S R$ AES revealed no contamination on the surface. The $\mathrm{Mo}(\mathrm{CO})_{6}, \mathrm{Cr}(\mathrm{CO})_{6}$, and $\mathrm{W}(\mathrm{CO})_{6}$ solid samples were purified by repeated evacuation in a gas manifold. The vapor, in equilibrium with the solid, was leaked into the UHV chamber and flowed through the system at constant pressures $\left(10^{-8}-10^{-6}\right.$ Torr $)$ during continuous turbomolecular pumping. Presence and purity of the metal hexacarbonyl gas was verified by residual gas analysis with a quadrupole mass spectrometer. The gas was maintained at constant pressure while the substrate is exposed to SR for one injection period of $3.5-5.5 \mathrm{~h}$. Total beam exposure Guring this period is typically $0.2-0.4 \mathrm{~A} \mathrm{~h}$. SR AES spectra were taken before and repeatedly throughout the exposure period.

\section{RESULTS AND DISCUSSION}

$\mathrm{Cr}(\mathrm{CO})_{6}, \mathrm{Mo}(\mathrm{CO})_{6}$, and $\mathrm{W}(\mathrm{CO})_{6}$ were deposited on sputter-cleaned Au substrate and $\mathrm{Mo}(\mathrm{CO})_{6}$ was deposited on sputter-cleaned $\mathrm{Si}(111)$ substrate. Figure 3 shows a series of Auger spectra obtained during the SR-induced deposition of $\mathrm{Mo}(\mathrm{CO})_{6}$. The spectra intensities have been normalized to incident beam current. The spectra obtained prior to leaking in the gas shows the characteristic AES features of Au. With each successive spectra taken during exposure to $\mathrm{Mo}(\mathrm{CO})_{6}$ gas and $\mathrm{SR}$, the Au signal reduces while features due to $\mathrm{Mo}, \mathrm{C}$, and $\mathrm{O}$ appear and increase in intensity.

Upon sufficient exposure within one beam fill, enough deposition has occurred to obscure any signal from the $\mathrm{Au}$ substrate, and all features can be attributed to deposited film.

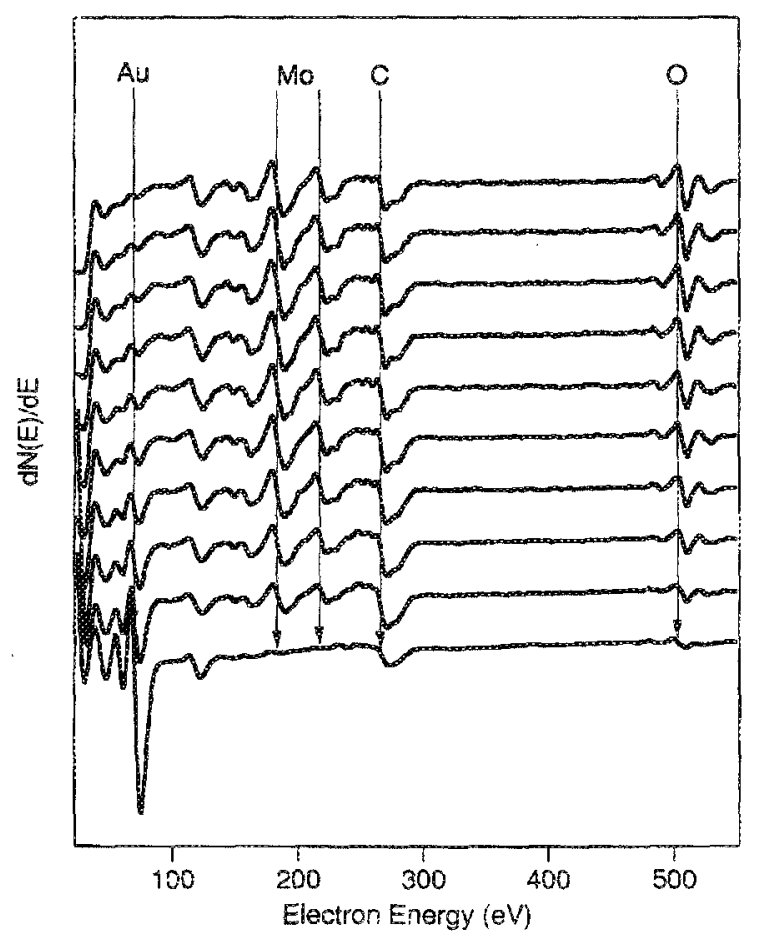

Fio. 3. A series of white light $S R$ excited Auger spectra acquired during deposition and photolysis at $1 \times 10^{-7}$ Torr of $\mathrm{Mo}(\mathrm{CO})_{6}$. The bottom spectrum is the substrate at the start of deposition. Each succeding spectrum above is taken after additional exposure during deposition. Total exposure was $0.35 \mathrm{~A} \mathrm{~h}$. 
Similar results are obtained for $\mathrm{W}(\mathrm{CO})_{6}$ and $\mathrm{Cr}(\mathrm{CO})_{6}$, with the Auger spectra of the deposited films compared in Fig. 4. Both $W$ and Mo films show significant contamination by both $\mathrm{C}$ and $\mathrm{O}$. The $\mathrm{Cr}$ film shows $\mathrm{O}$ contamination, although the relative quantity is difficult to discern because the $\mathrm{Cr}$ and O features overlap. There is less $\mathrm{C}$ present in the $\mathrm{Cr}$ film than for $\mathrm{W}$ and $\mathrm{Mo}$. Indeed, when $\mathrm{Cr}$ was deposited for a suficient period of time on a $C$ contaminated Au substrate, the $C$ signal reduces with exposure until the film is predominately $\mathrm{Cr}$ and $\mathrm{O}$ (Fig. 5). This is consistent with studies where chromium oxides have been deposited from $\mathrm{Cr}(\mathrm{CO}) 6^{16}$

The predominant contamination of $\mathrm{Cr}$ by $\mathrm{O}$, and $\mathrm{Mo}$ and $W$ by $C$ and $O$, is similar to that observed in other deposition techniques," 16 and agrees with the energetics proposed for these systems. ${ }^{17}$ This suggests that the metal carbonyls cannot be used for the deposition of clean films by SR-induced CVD under these conditions. However, it may be possible to adapt this process for the deposition of metal carbide or metal oxide films.

The rate of film growth during SR CVD from Mo(CO) 6 was determined by measuring the change in intensity of the Au Auger feature at $69 \mathrm{eV}$ as a function of integrated beam exposure. These rates were determined for a range of sample gas pressure from $3 \times 10^{-8}$ to $3 \times 10^{-7}$ Torr. The initial deposition rate was found to increase monotically with sample gas pressure within this range (Fig. 6). This suggests that for these deposition conditions the absorbance of the gas on the surface is the rate limiting step for deposition. The deposited film thickness from $\mathrm{Mo}(\mathrm{CO})_{6}$ can be estimated by assuming an attenuation length of $5 \AA$ for the $69 \mathrm{eV}$ Au Auger electron, as for a Mo thin film. ${ }^{18}$ This results in an initial deposition rate of $\sim 43-283 \AA$ Amp $h$ over this pressure range. While deposition rates at these pressures may not be technologically attractive, the pressure dependence of the

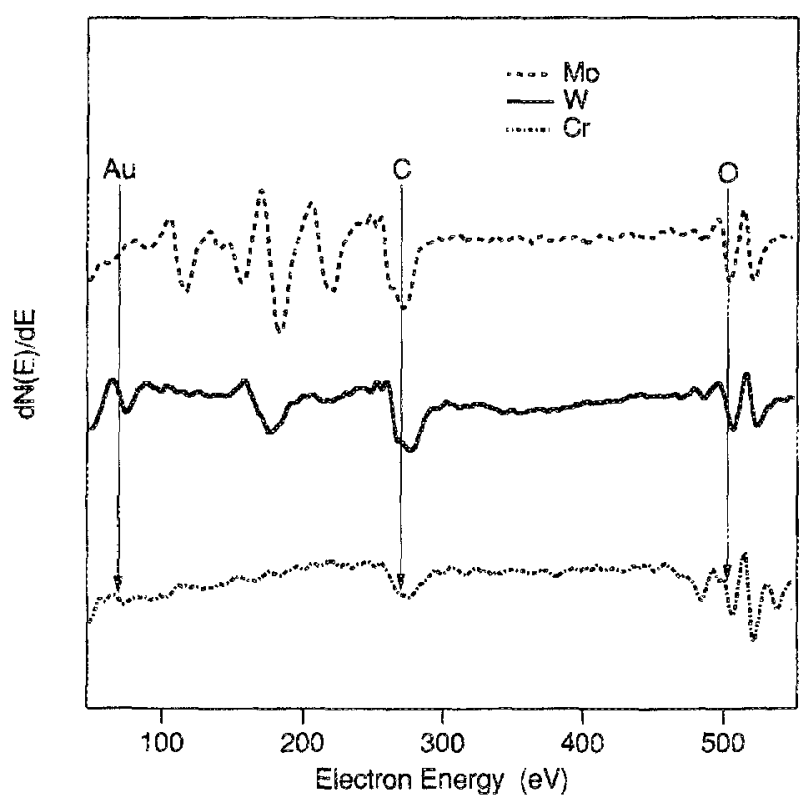

F1G. 4. White light SR excited Auger spectra for all three metal hexacarbonyls at the end of an exposure period. Arrows indicate position of Auger spectrai features for the substrates and contaminants.

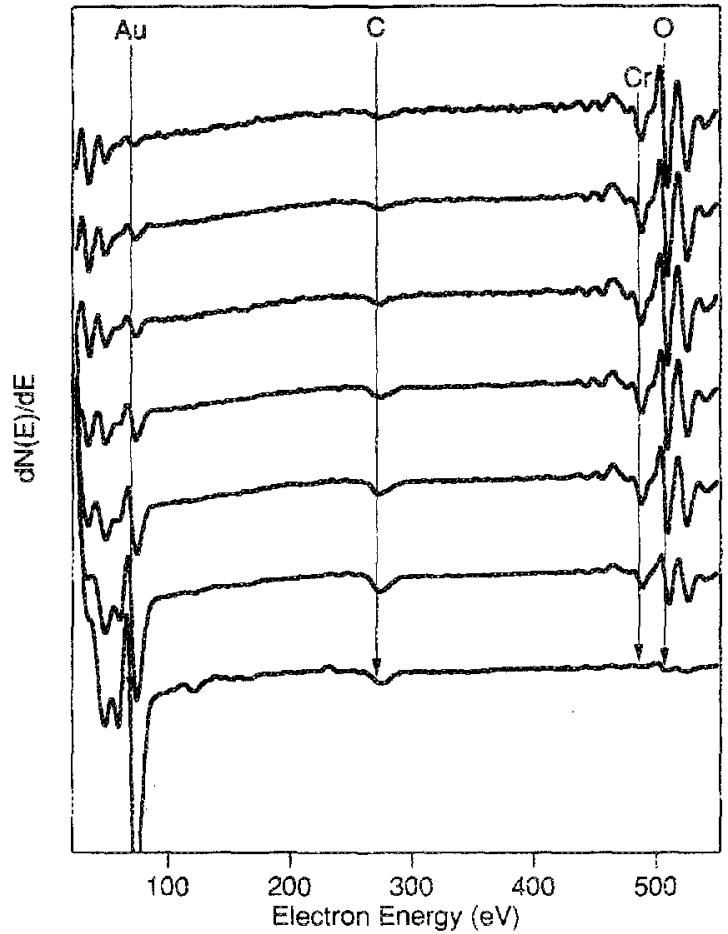

Fic. 5. A series of white light SR excited Auger spectra acquired during deposition of $\mathrm{Cr}(\mathrm{CO})_{6}$. The hottom spectrum is the substrate at the start of deposition. The substrate shows evidence of Contamination prior to deposition. There is an slight increase in $\mathrm{C}$ upon initial deposition of $\mathrm{Cr}$. After additional exposure, the $\mathrm{C}$ signal reduces with growth of fim containing $\mathrm{Cr}$ and $\mathrm{O}$. Total exposure was $0.3 \mathrm{~A} h$.

rate suggests that useful rates may be achieved at greater pressures. However, further studies are required before one may extrapolate these results to higher pressures and thicker films.

Note that the film deposition was localized to area of SR exposure in all cases, and no film deposition was observed by AES in areas unexposed to SR after prolonged dosing by sample gas. This suggests that the deposition depends on a surface excitation mechanism, and that there is the potential for using SR-induced CVD for patterning in $x$-ray lithography.

Attempts where made to deposit films in the presence of $5 \times 10^{-7}$ Torr of $\mathrm{Mo}(\mathrm{CO})_{6}$ using a 4-mm UV-grade sapphire filter and a $10 \mu \mathrm{Be}$ thin film filter. In both cases no appreciable film growth was observed during a beam fill. Since the sapphire filter allows $56 \%$ of the light with energy less than $8 \mathrm{eV}$ to pass, the flux due to UV photons $(<8 \mathrm{eV})$ from our broadband SR source does not contribute appreciably to deposition. Similar effects have been reported for photolysis of $\mathrm{Mo}(\mathrm{CO})_{6}$ on $\mathrm{Si}^{19,20}$ While Be filter allows most of the $\mathrm{x}$ rays with energy greater than $800 \mathrm{eV}$ to pass (Fig. 2), the total flux is two orders of magnitude less than that for broadband SR. Thus, while photons more energetic than 800 $\mathrm{eV}$ may induce deposition at higher fluxes, they do not make a significant contribution to mechanism of deposition for our SR source. Finally, these experiments could not determine whether the deposition is due to direct photon process, or due to secondary electrons generated at the substrate, 


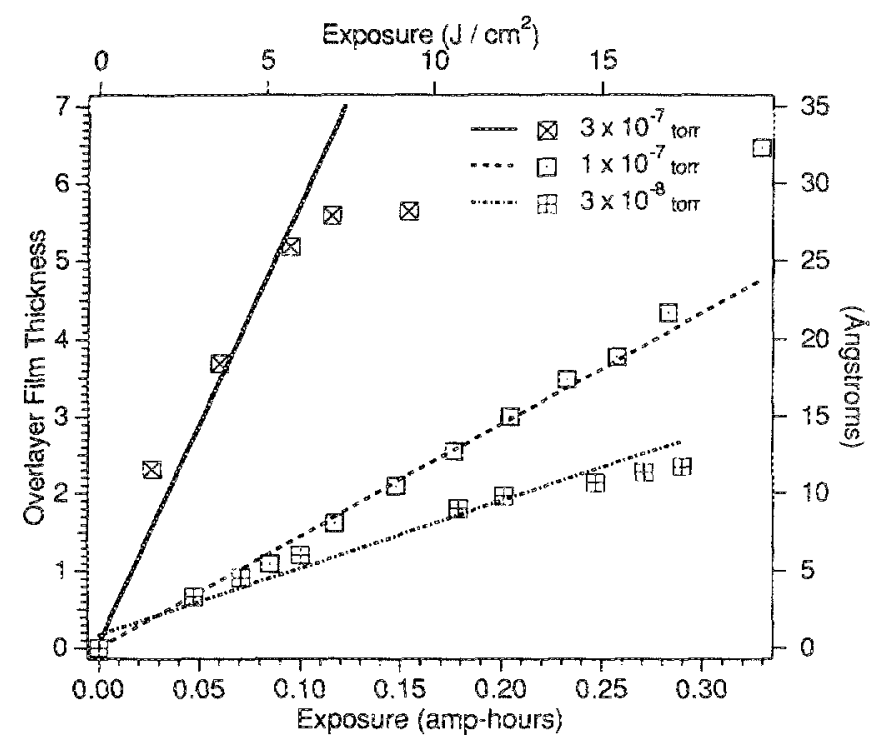

Fic. 6. Overlayer thickness as a function of total exposure for deposition of films from Mo(CO), at three pressures. Overlayer thickness is given in attenuation lengths of the $69 \mathrm{eV}$ Au Auger electron on the right-hand axis and in $A$ equivalent of Mo on the left-hand side; exposure to $S R$ is given in amp hours of storage ring beam current on the bottom axis and in estimatet $J / \mathrm{cm}^{2}$ on the top.

since both of these processes may have significant cross sections in the range of interest $(8-800 \mathrm{eV})$.

\section{CONCLUSIONS}

Broadband SR induces appreciable localized deposition of thin films in the presences of metal hexacarbonyl vapor at room temperature. No deposition was observed for $\mathrm{SR}$ filtered by a $4-\mathrm{mm}$ sapphire window or a $10 \mu$ Be filter. Deposition rate increases with the pressure of the gas in the range of $10^{-8}-10^{\cdots \cdot}$ Torr. Carbon and oxygen are incorporated in the deposited fims. Thus, under these deposition conditions, $\mathrm{Cr}(\mathrm{CO})_{6}, \mathrm{Mo}(\mathrm{CO})_{6}$, and $\mathrm{W}(\mathrm{CO})_{6}$, are not useful source compounds for the deposition of pure metal films. In fims deposited from $\mathrm{Cr}(\mathrm{CO})_{6}$, metal and metal oxide predominate. While for films from $\mathrm{W}(\mathrm{CO})_{6}$ and $\mathrm{Mo}(\mathrm{CO})_{6}$, the deposited metal is contaminated with carbide and residual carbonyl. This suggests the possibility of adapting SR induced
CVD of metal hexacarbonyls for use in the patterned deposition of the metal oxide and metal carbide films.

\section{ACKNOWLEDGMENTS}

This work was funded in part by the AFOSR through Contract No. F30602-80-C-0113 administered by Rome Air Development Center. D.C.M. acknowledges salary suppork from the U. W. CXrL. We thank Yoon Gi Kim and Helen Farrel for their experimental assistance. The University of Wisconsin Synchrotron Radiation Center receives its funding from the NSF.

\footnotetext{
a) Present address: Department of Hhysics, Case Western Reserve University, Cleveland OH.
}

'P. A. Dowben, J. T. Spencer, and G. T. Staut, Mater. Sci. Eng. B 2, 297 (1989).

'D. 3. Ehrlich, Solid State Technol. 28, 81 (1985).

D. J. Fhrtich, R. M. Osgood, Jr., and T. F. Deutsch, J. Electrochem. Soc. $128,2039(1981)$.

4J. G. Black, D. J. Ehrlich, M. Rothschild, S. P. Doran, and J. H. C. Sedlacek, J, Vac. Sci. Technol. B 5, 419 (1987).

M. M. Oprysko, and M. W. Buranek, J. Vac. Sci. Technol. B 5, 496 (1987).

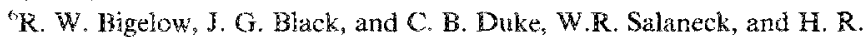
Thomas, Thin Solid Films 94, 233 (1982).

TT. M. M. M., Appl. Phys. 53, 8462 (1982).

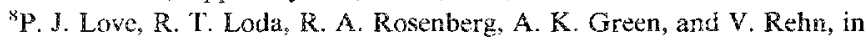
Laser Assisted Deposition, Wtching, and Doping (Society of Photo-Optical Instrumentation Wngineers, SPIE, 1984), p. 25.

"R. L. Jackson, G. W. Tyndall, and S. D. Sather, Appl. Surf. Sci. 36, 119 (1989).

"K. A. Singmaster, F. A. Houle, and R. J. Wilson, in Chemical Perspectives of Microefectronic Materials, edited by M. E. Gross, J. M. Jasinski, and John T. Yates (Materials Research Society, 1989), p. 469.

${ }^{11} \mathrm{C}$. M. Friend, I. R. Swanson, and F. A. Hlitsch, in Ref. 10, p. 461.

${ }^{12} \mathrm{~A}$. Heuberger, Microcircuit Eng. 86 (1987).

${ }^{13}$ N. M. Ceglio, $\mathbb{I}$. X-Ray Sci. Technol. 1 , 7 (1989).

${ }^{14}$ C. J. Pruett, Rev. Sci. Instrum. 60, 1913 (1989).

${ }^{15}$ R. A. Rosenberg, and D. C. Mancini, Nucl. Instrum. Methods A 29, 101 (1990).

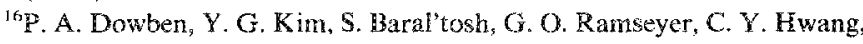
and M. Onellion, J. Appl. Phys. 67, 5658 (1990).

${ }^{17}$ D. C. Mancini, S. Varma, Y. G. Kim, R. R. Birge, R. A. Rosenberg, and P. A. Dowben, (to be piblished).

${ }^{18} \mathrm{C}$. J. Powell, Surf. Sci. 44,29 (1974).

"R. Zanoni, M. N. Piancasteli, J. McKinley, and G. Margaritondo, Appl. Phys. Lett. 55, 1020 (1989).

${ }^{20}$ R. Zanoni, M. N. Piancastelli, J. T. McKinley, and G. Margaritondo, Phys. Scr. 41, 636 (1990). 